\title{
Using a Spreadsheet Scroll Bar to Solve Equilibrium Concentrations
}

\author{
Andrés Raviolo* \\ Universidad Nacional de Río Negro y Universidad Nacional del Comahue, Bariloche 8400, Argentina
}

ABSTRACT: A simple, conceptual method is described for using the spreadsheet scroll bar to find the composition of a system at chemical equilibrium. Simulation of any kind of chemical equilibrium can be carried out using this method, and the effects of different disturbances can be predicted. This simulation, which can be used in general chemistry university courses (and also in the higher years of secondary schools due to its simplicity), is carried out by the students, avoids the solving of complex algebraic equations, and allows many of the common misconceptions and difficulties in this subject to be dealt with.

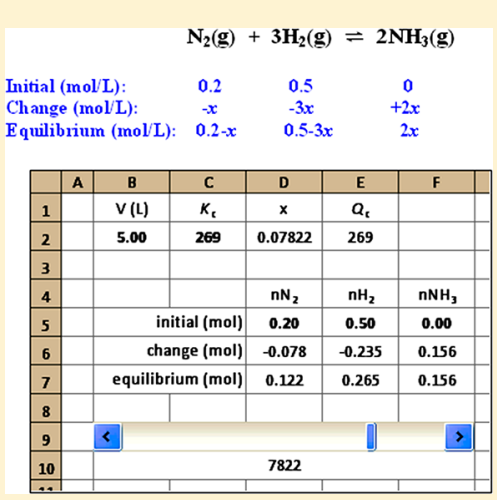

KEYWORDS: High School/Introductory Chemistry, First-Year Undergraduate/General, Physical Chemistry, Computer-Based Learning, Misconceptions/Discrepant Events, Acids/Bases, Equilibrium

\begin{abstract}
A simple, conceptual method is described for using the spreadsheet scroll bar to work out the composition of a system at chemical equilibrium. This method allows the simulation of any kind of chemical equilibrium (homogeneous gas, acid-base, etc.) and predicts the effects of different disturbances. Among the advantages of using spreadsheets for the teaching of chemistry, the most important are (a) they can be learned rapidly and used immediately, (b) in many cases they can replace programming language that is difficult to learn, and (c) their suitability for modeling to answer questions such as "what would happen if...?".

Chemical equilibrium is an abstract subject that students find difficult. Much research has been carried out on students' misconceptions regarding this topic at different educational levels, particularly concerning a system at equilibrium that has been disturbed and the application of Le Châtelier's principle. With respect to conceptions held in relation to the composition of a system at chemical equilibrium, studies have shown that
\end{abstract} some students:

- do not distinguish between the initial composition and that of the equilibrium or do not acknowledge the coexistence of all the species in the equilibrium. ${ }^{2}$

- believe that the quantities of reactants and products present in the equilibrium are equal to each other, or are equal to the stoichiometric coefficients. ${ }^{3-5}$

- become confused when relating the concepts of limiting reactants and the composition of chemical equilibrium. ${ }^{6}$

The spreadsheet scroll bar approach, which can be used in general chemistry university courses (and also in the higher years of secondary schools, due to its simplicity), allows the composition of a chemical system at equilibrium to be worked out by applying stoichiometric principles, differentiating amounts (moles) from concentrations (molarities), thus dealing with some of the misconceptions described.

In many cases, to determine the concentration of all the species in a system at chemical equilibrium, it is necessary to solve quadratic, cubic, and quartic polynomial equations. One of the first spreadsheet applications for the resolution of this kind of equation related to chemical equilibrium can be found in Breneman, ${ }^{7}$ where the roots of these polynomials are determined through a repetitive procedure based on the Newton-Raphson method, requiring the use of differential calculus. Other authors, basing their work on thermodynamic aspects and minimizing Gibbs energy as a function of the extent of the reaction, have calculated the composition of the equilibrium (a) with the spreadsheet ${ }^{8}$ or (b) with a specific program. ${ }^{9}$ Allendoerfer ${ }^{10}$ designed the Equilibrium Calculator program for the calculation of equilibrium concentrations, adapting the Campanario and Ballesteros ${ }^{11}$ program and using the numerical method discussed by Weltin as a base. ${ }^{12,13}$ Joshi $^{14}$ used methods suitable for students of analytical and physical chemistry to find the partial pressures of the species when the reaction reached equilibrium, relying on the use of macros. Another two proposals for using the spreadsheet, simpler and suitable for an introductory course, although they do not make use of the scrollbar, are found in Metz and Donato $^{15}$ and Finnemore. ${ }^{16}$ Vander Griend ${ }^{17}$ has recently modeled chemical equilibrium on Excel, with a program that uses macros. This program calculates the reaction quotient, Gibbs energy and $\Delta G$.

To sum up, most of the proposals found in the literature to determine the composition of a system at chemical equilibrium are already developed or predesigned, and the students use

Published: September 6, 2012 
them as a ready-made tool. Some involve computing difficulties, such as the inclusion of macros, and others entail certain mathematical difficulties. One of the overwhelming advantages of the method presented here is that the spreadsheets are created entirely by the students because they entail a minimum of computing and mathematical complexity.

\section{CHEMICAL EQUILIBRIUM IN THE GAS PHASE}

A typical chemical equilibrium problem requires working out the composition of all the species in the system at chemical equilibrium from the initial concentrations and the value of the equilibrium constant at a given temperature. For the synthesis of ammonia, for example, the following solution is suggested:

$$
\begin{aligned}
& \mathrm{N}_{2}(\mathrm{~g})+3 \mathrm{H}_{2}(\mathrm{~g}) \rightleftharpoons 2 \mathrm{NH}_{3}(\mathrm{~g}) \\
& K_{\mathrm{C}}=\frac{\left[\mathrm{NH}_{3}\right]^{2}}{\left[\mathrm{~N}_{2}\right]\left[\mathrm{H}_{2}\right]^{3}}
\end{aligned}
$$

If the equilibrium constant $K_{\mathrm{C}}$ for this reaction is 269 at 500 $\mathrm{K}$, and the initial reactant concentrations are $0.2 \mathrm{~mol} / \mathrm{L}$ of nitrogen and $0.5 \mathrm{~mol} / \mathrm{L}$ of hydrogen, then the problem can be presented in the following way:

$\begin{array}{lccc} & \mathrm{N}_{2}(\mathrm{~g})+3 \mathrm{H}_{2}(\mathrm{~g}) & 2 \mathrm{NH}_{3}(\mathrm{~g}) \\ \text { Initial }(\mathrm{mol} / \mathrm{L}): & 0.2 & 0.5 & 0 \\ \text { Change }(\mathrm{mol} / \mathrm{L}): & -x & -3 x & +2 x \\ \text { Equilibrium }(\mathrm{mol} / \mathrm{L}): & 0.2-x & 0.5-3 x & 2 x\end{array}$

The expression of the equilibrium constant in terms of a single unknown quantity would be:

$$
K_{\mathrm{C}}=\frac{[2 x]^{2}}{[0.2-x][0.5-3 x]^{3}}
$$

An equation with $x$ to the power of 4 is thus obtained, which is not easy to solve for $x$. This equation can be written in the usual way: $\mathrm{a} x^{4}+\mathrm{b} x^{3}+\mathrm{c} x^{2}+\mathrm{d} x+\mathrm{e}=0$. Although graphing calculators (e.g., TI-84) now have an equation solver that makes this calculation easier, the method proposed below offers a simple interactive environment that enables simulations of different chemical equilibrium situations to be carried out.

The previous expression of the equilibrium constant is also generally expressed in relation to the amount and the volume. Suppose that the initial amount of $\mathrm{N}_{2}$ and $\mathrm{H}_{2}$ are 0.2 and 0.5 mol, respectively, in a volume of $5 \mathrm{~L}$.

$$
\begin{aligned}
K_{\mathrm{C}} & =\frac{n_{\mathrm{NH}_{3}}{ }^{2} V^{2}}{n_{\mathrm{N}_{2}} n_{\mathrm{H}_{2}}{ }^{3}} \\
K_{\mathrm{C}} & =\frac{(2 x)^{2} 5^{2}}{(0.2-x)(0.5-3 x)^{3}}
\end{aligned}
$$

To avoid solving this quartic equation analytically, the simulation method proposed consists of assigning a range of possible values to $x$ using the spreadsheet scroll bar and, on the basis of stoichiometric relationships, determining the quantities or concentrations of the reactants and products in the equilibrium. With these concentrations, the resulting values of $K_{\mathrm{C}}$ can be calculated. The final solution is the composition of the system when the value of $Q_{C}$ coincides with, or is closest to, its known value $\left(K_{\mathrm{C}}\right)$ at the given temperature. The

\begin{tabular}{|c|c|c|c|c|c|c|}
\hline & A & B & C & D & $\mathbf{E}$ & $\mathbf{F}$ \\
\hline 1 & & $V(L)$ & $K_{\mathrm{c}}$ & $x$ & $a_{\mathrm{c}}$ & \\
\hline 2 & & 5.00 & 269 & 0.07822 & 269 & \\
\hline 3 & & & & & & \\
\hline 4 & & & & $\mathrm{nN}_{2}$ & $\mathrm{nH}_{2}$ & $\mathrm{nNH}_{3}$ \\
\hline 5 & & \multicolumn{2}{|c|}{ initial (mol) } & 0.20 & 0.50 & 0.00 \\
\hline 6 & & \multicolumn{2}{|c|}{ change (mol) } & -0.078 & -0.235 & 0.156 \\
\hline 7 & & \multicolumn{2}{|c|}{ equilibrium (mol) } & 0.122 & 0.265 & 0.156 \\
\hline \multicolumn{7}{|l|}{8} \\
\hline 9 & & \multicolumn{4}{|l|}{$<$} & $>$ \\
\hline 10 & & \multicolumn{5}{|c|}{7822} \\
\hline
\end{tabular}
composition of the mixture at equilibrium, to be solved in this problem, will be that corresponding to $K_{\mathrm{C}}=269$ (Figure
1). In cell B10, a number between 1 and 10,000 will appear, which is assigned with the scroll bar.

Figure 1. Simulation to determine the composition of the system at chemical equilibrium. The operations are cell D2 $=$ B10/100000, cell $\mathrm{D} 6=-1 * \mathrm{D} 2$, cell $\mathrm{E} 6=-3 * \mathrm{D} 2$, cell $\mathrm{F} 6=2 * \mathrm{D} 2$, cell $\mathrm{D} 7=\mathrm{D} 5+\mathrm{D} 6$, cell $\mathrm{E} 7=\mathrm{E} 5+\mathrm{E} 6$, cell $\mathrm{F} 7=\mathrm{F} 5+\mathrm{F} 6$, and cell $\mathrm{E} 2=\mathrm{F} 7^{\wedge} 2 /\left(\mathrm{D} 7^{*} \mathrm{E} 7^{\wedge} 3\right)^{*} \mathrm{~B} 2^{\wedge} 2$.

The scroll bar, a tool present on all spreadsheets, allows the incorporation or rapid adjustment of values found within a certain interval. To insert the scroll bar into the 2007 version of the Microsoft Excel program, for example, click on the Office button, Excel options. Select the Popular tab, then the Developer tab and select Show developer tab in ribbon. Following this, select Insert, Form controls, Scrollbar. Once the scroll bar has been inserted, Format Control can be opened on it, and Minimum value (0), Maximum value (10,000), Incremental change (1), and Cell link ( $\$ \mathrm{~B} \$ 10)$ are completed.

Given that decimal numbers cannot be inserted as the minimum value, in cell $\mathrm{C5}$ the previous value is divided by $100,000\left(1 \times 10^{-5}\right)$ and the result constitutes $x$. In this way, $x$ can increase by $1 \times 10^{-5}$, from 0 to 0.1 . In other problems, depending on the value of $K$, to obtain a value close to this in the simulation it may be necessary to change the number 100,000 for a larger number.

\section{THE EFFECT OF A CHANGE IN TOTAL VOLUME ON THE COMPOSITION OF THE SYSTEM}

This simulation enables students to answer the question: what would happen if... ?; for example, what happens if the total volume of the system is modified, at a constant temperature? Given that the spreadsheet drawn up allows students to enter data on the total volume of the system, the effects of a change in volume on the composition of the mixture can be simulated, and the predictions made using the Le Chatelier principle or analyzing the expression of $K_{C}$ can be verified (Table 1 ). In accordance with the Le Châtelier principle, it is seen that with an increase in volume, at constant temperature, smaller amounts of ammonia are obtained in the mixture at equilibrium.

Table 1. The Composition at Equilibrium for Different Volumes of the System

$\begin{array}{ccccc}\text { Volume } / \mathrm{L} & n_{\text {eq }} \mathrm{N}_{2} / \mathrm{mol} & n_{\text {eq }} \mathrm{H}_{2} / \mathrm{mol} & n_{\text {eq }} \mathrm{NH}_{3} / \mathrm{mol} & K_{\mathrm{C}} \\ 5 & 0.122 & 0.265 & 0.156 & 269 \\ 10 & 0.142 & 0.327 & 0.116 & 269 \\ 15 & 0.154 & 0.361 & 0.093 & 269 \\ 20 & 0.161 & 0.383 & 0.078 & 269\end{array}$


As mentioned previously, the method presented is original in its simplicity, and its aim is for the students to develop it on their own. After carrying out and explaining the example above, the teacher can ask the students to solve the following problem using a similar simulation: If in an experiment $2.0 \times 10^{-2} \mathrm{~mol}$ of $\mathrm{NO}, 8.0 \times 10^{-3} \mathrm{~mol}$ of $\mathrm{Cl}_{2}$, and $6.8 \mathrm{~mol}$ of $\mathrm{NOCl}$ are mixed in a recipient of $2.0 \mathrm{~L}$ at $35^{\circ} \mathrm{C}$, in which direction does the system reach equilibrium? What is the composition of the mixture at equilibrium? What is the composition of the equilibrium if the volume of the system changes to $5.0 \mathrm{~L}$ at constant temperature? Are the predictions made by applying Le Châtelier's principle fulfilled?

$$
\begin{gathered}
2 \mathrm{NO}(\mathrm{g})+\mathrm{Cl}_{2}(\mathrm{~g}) \rightleftharpoons 2 \mathrm{NOCl}(\mathrm{g}) \\
K_{\mathrm{C} 35^{\circ} \mathrm{C}}=6.5 \times 10^{4}
\end{gathered}
$$

\section{THE EFFECTS OF DILUTION OF A WEAK ACID}

When water is added to a weak acid solution, it becomes less acidic; that is, the concentration of $\mathrm{H}^{+}$ions decreases and the $\mathrm{pH}$ increases. However, according to the Le Châtelier principle, to counteract the "disturbance" (the dilution), the equilibrium shifts toward the formation of more ions. This apparent contradiction is resolved by comparing the $\mathrm{pH}$ with the percentage of dissociation. The more dilute the acid solution is, the higher the percentage of dissociation will be, even though the concentration of $\mathrm{H}^{+}$ions decreases.

In simplified form, the equilibrium equation for a weak acid with an initial concentration of $0.1 \mathrm{~mol} / \mathrm{L}$ can be expressed as follows:

Initial (mol/L): Change (mol/L): $\mathrm{HA}(\mathrm{ac}) \rightleftharpoons \mathrm{A}^{-}(\mathrm{ac})+\mathrm{H}^{+}(\mathrm{ac})$ Equilibrium (mol/L): 0.1 $-x$ $\begin{array}{rr}0 & 0 \\ +x & +x \\ x & x\end{array}$

$$
\begin{aligned}
& K_{\mathrm{a}}=\frac{\left[\mathrm{A}^{-}\right]\left[\mathrm{H}^{+}\right]}{[\mathrm{HA}]} \\
& K_{\mathrm{a}}=\frac{n_{\mathrm{A}^{-}} n_{\mathrm{H}^{+}}}{n_{\mathrm{HA}} V}
\end{aligned}
$$

In an analogous way to the previous simulation for ammonia, the composition of an acid-base system at equilibrium can be found (Figure 2); for example, for the dissociation of acetic acid, $K_{\mathrm{a}}=1.8 \times 10^{-5}$ at $25^{\circ} \mathrm{C}$. Varying the volume for the same initial amount of acid, for example, $1 \mathrm{~mol}$, the new composition of the system can quickly be found by shifting the cursor of the scroll bar until the value of equilibrium constant $K_{\mathrm{a}}$ is again reached. In cell B10, a number between 1 and 2000 will appear, which is assigned with the scroll bar. To fit into the scale of $K_{a}$ the number $x$ obtained from the scroll bar is divided by 100,000 (cell D2). This value, $x$, constitutes the change in amount expressed in cells D6, E6, and F6. The final solution is the composition of the system when the value of $Q_{a}$ coincides with its known value $\left(K_{\mathrm{a}}\right)$ at the given temperature.

Values found for four different volumes are shown in Table 2. Results that are equal for $\mathrm{pH}$ and dissociation will be obtained if the volume is held constant at $1 \mathrm{~L}$ and the initial amount of acid is changed to $2,1,0.5$, and 0.1 , respectively.

In short, with this simulation, the results predicted by the Le

\begin{tabular}{|c|c|c|c|c|c|c|c|}
\hline & A & B & C & D & $E$ & $\mathbf{F}$ & G \\
\hline 1 & & $V(L)$ & $K a$ & $\mathbf{x}$ & $Q \mathbf{a}$ & $\mathrm{pH}$ & $\begin{array}{c}\% \\
\text { dissociation }\end{array}$ \\
\hline 2 & & 10.00 & $1.80 E-05$ & 0.01333 & $1.80 \mathrm{E}-05$ & 2.9 & 1.3 \\
\hline 3 & & & & & & & \\
\hline 4 & & & & nAH & nA- & $\mathrm{nH}+$ & \\
\hline 5 & & \multicolumn{2}{|c|}{ initial (mol) } & 1.00 & 0.00 & 0.00 & \\
\hline 6 & & \multicolumn{2}{|c|}{ change (mol) } & -0.013 & 0.013 & 0.013 & \\
\hline 7 & & \multicolumn{2}{|c|}{ equilibrium (mol) } & 0.987 & 0.013 & 0.013 & \\
\hline \multicolumn{8}{|l|}{8} \\
\hline 9 & & \multicolumn{3}{|l|}{$<$} & \multicolumn{2}{|r|}{$>$} & \\
\hline 10 & & \multicolumn{5}{|c|}{1333} & \\
\hline
\end{tabular}
Châtelier principle can be verified, and the amounts and concentrations are explicitly differentiated, an aspect with which many students have difficulty. ${ }^{6}$ In addition to avoiding having
Figure 2. A simulation for weak acid where new values for volume are inserted. The operations are cell D2 $=\mathrm{B} 10 / 100000$, cell D6 $=-1 * \mathrm{D} 2$, cell E6 $=1 * \mathrm{D} 2$, cell $\mathrm{F} 6=1 * \mathrm{D} 2$, cell $\mathrm{D} 7=\mathrm{D} 5+\mathrm{D} 6$, cell $\mathrm{E} 7=\mathrm{E} 5+\mathrm{E} 6$, cell F7 $=$ F5+F6, cell E2 $=$ E7 $*$ F7 $/(\mathrm{D} 7 * \mathrm{~B} 2)$, cell F2 $=-\mathrm{LOG}(\mathrm{F} 7 / \mathrm{B} 2)$, and cell G2 $=\mathrm{F} 7 / \mathrm{D}^{*} 100$.

to solve the quadratic equation analytically, with this method, the use of the $5 \%$ rule to diminish or not the $x$ remaining in the denominator of the expression of $K_{\mathrm{a}}$ is also avoided. In addition, modifying the value of the initial amount of $\mathrm{A}^{-}$, for example, for fixed values of $\mathrm{HA}$ and volume, the common ion effect can be simulated.

\section{THE COMPOSITION OF A VERY DILUTE SOLUTION OF WEAK ACID}

Another application of this simulation is the case of a very weak or very dilute acid. If the concentration of $\mathrm{H}^{+}$ions is less than $10^{-6} \mathrm{~mol} / \mathrm{L}$, the autoprotolysis of the water contributes significantly to the $\mathrm{pH}$. To work out the composition of this system, where four species exist, $\mathrm{HA}, \mathrm{A}^{-}, \mathrm{H}^{+}$, and $\mathrm{OH}^{-}$, that is, four unknown variables, four equations are required. These equations are combined and the result obtained is a more complex expression of $K_{\mathrm{a}}:{ }^{18}$

$$
K_{\mathrm{a}}=\frac{\left[\mathrm{H}^{+}\right]\left(\left[\mathrm{H}^{+}\right]-\frac{K_{\mathrm{w}}}{\left[\mathrm{H}^{+}\right]}\right)}{[\mathrm{HA}] \text { initial }-\left[\mathrm{H}^{+}\right]+\frac{K_{\mathrm{w}}}{\left[\mathrm{H}^{+}\right]}}
$$

To find the value of $\left[\mathrm{H}^{+}\right]$, and also the $\mathrm{pH}$, a cubic equation must be solved:

$$
x^{3}+K_{\mathrm{a}} x^{2}-\left(K_{\mathrm{w}}+K_{\mathrm{a}}[\mathrm{HA}]_{\text {initial }}\right) x-K_{\mathrm{a}} K_{\mathrm{w}}=0
$$

Students can avoid solving this equation using the simulation proposed where the previous equation of $K_{\mathrm{a}}$ is replaced by this new, more complex one, that incorporates the value of $K_{W}=1.0$ $\times 10^{-14}$. Figure 3 presents the simulation that solves the exercise in Atkins and Jones, ${ }^{18}$ which requires the calculation of the $\mathrm{pH}$ of an aqueous solution of phenol (a very weak acid: $K_{\mathrm{a}}$ $=1.3 \times 10^{-10}$ ) with an initial concentration of $1.00 \times 10^{-4}$ $\mathrm{mol} / \mathrm{L}$. In cell B9, a number between 1 and 2000 will appear, which is assigned with the scroll bar. To fit into the scale of $K_{a}$, the number $x$ obtained from the scroll bar is divided by $100,000,000$. In an analogous way to the previous simulation for acetic acid, the final solution is the composition of the system when the value of $Q_{a}$ coincides with its known value $\left(K_{\mathrm{a}}\right)$ at the given temperature.

Given that the solution is electrically neutral, the charge balance is expressed as $\left[\mathrm{H}^{+}\right]=\left[\mathrm{OH}^{-}\right]+\left[\mathrm{A}^{-}\right]$, so the concentration at equilibrium of the anion $\mathrm{A}^{-}$is 
Table 2. Results for the Dilution of a Weak Acid

\begin{tabular}{|c|c|c|c|c|c|c|c|}
\hline $\mathrm{V} / \mathrm{L}$ & $n \mathrm{HA}$ initial $/ \mathrm{mol}$ & $n \mathrm{HA}$ eq $/ \mathrm{mol}$ & $\mathbf{n A}^{-}$eq $/ \mathrm{mol}$ & $n \mathrm{H}^{+}$eq $/ \mathrm{mol}$ & $K_{\mathrm{a}}$ & $\mathrm{pH}$ & Dissociation (\%) \\
\hline 0.5 & 1 & 0.997 & 0.003 & 0.003 & $1.79 \times 10^{-5}$ & 2.2 & 0.3 \\
\hline 1 & 1 & 0.996 & 0.004 & 0.004 & $1.80 \times 10^{-5}$ & 2.4 & 0.4 \\
\hline 2 & 1 & 0.994 & 0.006 & 0.006 & $1.80 \times 10^{-5}$ & 2.5 & 0.6 \\
\hline 10 & 1 & 0.987 & 0.013 & 0.013 & $1.80 \times 10^{-5}$ & 2.9 & 1.3 \\
\hline
\end{tabular}

\begin{tabular}{|c|c|c|c|c|c|c|}
\hline & A & B & C & D & $E$ & $\mathbf{F}$ \\
\hline 1 & & $K w$ & $K a$ & $x$ & Qa & $\mathrm{pH}$ \\
\hline 2 & & $1.0 \mathrm{E}-14$ & 1.3E-10 & $1.5 \mathrm{E}-07$ & $1.3 \mathrm{E}-10$ & 6.8 \\
\hline 3 & & & & & & \\
\hline 4 & & & & [HA] & {$[\mathrm{A}-\mathrm{]}$} & {$[\mathrm{H+}]$} \\
\hline 5 & & \multicolumn{2}{|c|}{ initial (mol/L) } & $1.00 \mathrm{E}-04$ & 0.00 & 0.00 \\
\hline 6 & & \multicolumn{2}{|c|}{ equilibrium (mol/L) } & $9.99 \mathrm{E}-05$ & $8.33 E-08$ & $1.50 \mathrm{E}-07$ \\
\hline \multicolumn{7}{|l|}{7} \\
\hline 8 & & $<$ & & & & $>$ \\
\hline 9 & & \multicolumn{5}{|c|}{15} \\
\hline
\end{tabular}

Figure 3. Simulation to determine the system composition for an aqueous solution of a very weak acid. The operations are cell D2 = B9/ 100000000 , cell $\mathrm{F} 6=\mathrm{F} 5+\mathrm{D} 2$, cell $\mathrm{E} 2=(\mathrm{F} 6 *(\mathrm{~F} 6-\mathrm{B} 2 / \mathrm{F} 6)) /(\mathrm{D} 5-$ $(\mathrm{F} 6+\mathrm{B} 2 / \mathrm{F} 6))$, cell E6 = F6-(B2/F6), and cell D6 =D5-E6.

$$
\left[\mathrm{A}^{-}\right]=\left[\mathrm{H}^{+}\right]-\frac{K_{\mathrm{w}}}{\left[\mathrm{H}^{+}\right]}
$$

At the same time, from the mass balance we can obtain the expression of the concentration of acid $\mathrm{HA}$ at equilibrium: $[\mathrm{HA}]_{\text {initial }}=[\mathrm{HA}]+\left[\mathrm{A}^{-}\right]$, where the concentration of the acid at equilibrium is $[\mathrm{HA}]=[\mathrm{HA}]_{\text {initial }}-\left[\mathrm{A}^{-}\right]$. For another very weak acid or another initial concentration of acid, the value of $K_{\mathrm{a}}$ and of $[\mathrm{AH}]_{\text {initial }}$ can simply be changed in the simulation, and with the scroll bar, the composition of the system and its $\mathrm{pH}$ is obtained.

\section{CONCLUSIONS}

A new way has been developed to tackle and solve chemistry problems related to the composition of a system at chemical equilibrium that emphasizes conceptual aspects (stoichiometry, solutions, chemical equilibrium) over the solution of algebraic equations. The procedure is simple and can be developed entirely by the students. It enables the students to deal with various of the misconceptions and difficulties in the subject of chemical equilibrium such as (a) the lack of differentiation between the initial situation and the situation at equilibrium, (b) the idea that the amounts present at equilibrium are equal to the stoichiometric coefficients, and (c) the confusion between amount and concentration.

In contrast to other proposals, this simulation can be applied directly in introductory university general chemistry courses, as it fits in with the treatment and depth given to the calculation of concentrations in a chemical equilibrium. It follows the same lines as most general chemistry textbooks used at this level, such as Chang ${ }^{19}$ or Brown, LeMay, Bursten, and Burge, ${ }^{20}$ for example, through the use of the ICE format (initial, change, and equilibrium). This simulation can be applied to all types of chemical equilibrium and allows students to confront complex concepts that are central to the subject. Attention is focused on the chemical aspects, such as application of the principles of the stoichiometric relationship, without introducing mathematical complexity, and polynomial equations are avoided.
Answers are obtained to questions such as: what would happen if...?; for example, what happens if we increase the volume of the system? Using this method, the principle of Le Châtelier can be quantitatively verified, overcoming the inconvenience of its use exclusively as a memory rule.

These simulations are initially constructed by the students in class, and later this type of activity can be given as homework or used for evaluation. Spreadsheet scrollbars can also be used for the verification and recreation of simulations that have already been carried out, in which the underlying mathematical models are not obvious. ${ }^{21}$

In their revision of the first 25 years of spreadsheets in education, Baker and Sugden ${ }^{1}$ highlight their potential, versatility, and accessibility, and state that despite their rising popularity, many of their possible applications have not yet been explored. In this work, a procedure is presented for performing simple, instantaneous, numerical simulations that can give students an opportunity to develop abilities in ICT, which can then be transferred to other contexts, in particular other scientific disciplines such as physics and mathematics.

This training in the use of spreadsheets is also useful during the development of topics in advanced chemistry. For example, $\mathrm{Lim}^{22}$ in the teaching of quantum chemistry, reported that students with weak mathematical backgrounds have profited more from the use of spreadsheets than from advanced mathematical packages requiring the use of symbolic, quasiprogramming language, which can present an additional learning obstacle for many students.

The method presented in this article can be of great significance to teachers interested in updating their teaching through methodological approaches such as problem-oriented activities and active learning by students.

\section{AUTHOR INFORMATION}

\section{Corresponding Author}

*E-mail: araviolo@bariloche.com.ar.

Notes

The authors declare no competing financial interest.

\section{REFERENCES}

(1) Baker, J.; Sugden, S. Spreadsheets Educ. 2003, 1, No. art 2.

(2) Van Driel, J.; De Vos, W.; Verloop, N.; Dekkers, H. Int. J. Sci. Educ. 1998, 20, 379-392.

(3) Hackling, M.; Garnett, P. Eur. J. Sci. Educ. 1985, 7, 205-214.

(4) Huddle, P.; Pillay, A. J. Res. Sci. Teach. 1996, 23, 65-77.

(5) Raviolo, A. Educ. Quim. 2006, 17, 300-307.

(6) Bergquist, W.; Heikkinen, H. J. Chem. Educ. 1990, 67, 10001003.

(7) Breneman, G. J. Chem. Educ. 1986, 63, 321-322.

(8) David, C. J. Chem. Educ. 1989, 66, A237-A238.

(9) Allendoerfer, R. J. Chem. Educ. 1993, 70, 388.

(10) Equilibrium Calculator, Version 4.22, RDA Chemware, 2010.

(11) Campanario, J. M.; Ballesteros, R. J. Comp. Math. Sci. Teach. 1991, 10, 87.

(12) Weltin, E. J. Chem. Educ. 1990, 67, 548.

(13) Weltin, E. J. Chem. Educ. 1991, 68, 486-487. 
(14) Joshi, B. J. Chem. Educ. 1994, 71, 551-554.

(15) Metz, C.; Donato, H. J. Chem. Educ. 1989, 66, A241-A242.

(16) Finnemore, D. Sch. Sci. Rev. 1990, 71, 94-98.

(17) Vander Griend, D. J. Chem. Educ. 2011, 88, 1727-1729.

(18) Atkins, P.; Jones, L. Chemical Principles, 3th ed.; Freeman and Company: New York, 2005.

(19) Chang, R. Chemistry, 10th ed.; McGraw-Hill: New York, 2010.

(20) Brown, T.; LeMay, D; Bursten, B; Burdge, J. Chemistry: The

Central Science, 9th ed.; Pearson Education: Upper Saddle River, NJ, 2003.

(21) Raviolo, A. Educ. Quim. 2012, 23, 11-15.

(22) Lim, K. J. Comput. Chem. Jpn. 2006, 5, 139-146. 